\title{
Cure Cycle Effect on High-Temperature Polymer Composite Structures Molded by VARTM
}

\begin{abstract}
Ahmed Khattab
Department of Industrial Technology, College of Engineering, University of Louisiana at Lafayette, P.O. Box 42972, Lafayette, LA 70504, USA

Correspondence should be addressed to Ahmed Khattab; khattab@louisiana.edu

Received 9 January 2013; Accepted 17 March 2013

Academic Editor: Nikhil Gupta

Copyright (C) 2013 Ahmed Khattab. This is an open access article distributed under the Creative Commons Attribution License, which permits unrestricted use, distribution, and reproduction in any medium, provided the original work is properly cited.

This paper presents an analytical and experimental investigation of cure cycle effect on carbon-fiber reinforced high-temperature polymer composite structures molded by vacuum assisted resin transfer molding (VARTM). The molded composite structure consists of AS4-8 harness carbon-fiber fabrics and a high-temperature polymer (Cycom 5250-4-RTM). Thermal and resin cure analysis is performed to model the cure cycle of the VARTM process. The temperature and cure variations with time are determined by solving the three-dimensional transient energy and species equations within the composite part. Several case studies were investigated by the developed analytical model. The same cases were also experimentally investigated to determine the ultimate tensile strength for each case. This study helps in developing a science based technology for the VARTM process for the understanding of the process behavior and the effect of the cure cycle on the properties of the molded high-temperature polymer composites.
\end{abstract}

\section{Introduction}

Nonautoclave molding technology, such as vacuum assisted resin transfer molding (VARTM), offers a more cost effective manufacturing process for composite materials than the resin transfer molding (RTM) and autoclave/prepreg technique. However, its potential for fabricating high-temperature polymer composites needs to be explored. Process variables, including the maximum cure temperature, cure time, and postcure cycles have significant effects on the resulting composite [1-7]. Golestanian and El-Gizawy [1] presented results on cure-dependent properties of resin transfer molded thin composites with woven fiber mats. In their study, resin properties are assumed to change from viscoelastic liquid to properties of the solid as the part cures. Khattab and ElGizawy [4] developed an analytical model to determine the cure-dependent mechanical properties as functions of degree of cure for high-temperature polymer composites molded by VARTM.

Kim and Daniel [5] conducted an experimental study to investigate the cure cycle effects on residual stress and residual strain on composite material structures fabricated by resin transfer molding process. Three different cure cycles with different peak temperature and different heat rates were used. The study showed that the residual stress developed at high cure temperature was lower than that developed at a lower cure temperature due to the constraint induced strain. The effect of different heat-up rates was not that clear. Liu et al. [6] experimentally investigated the effects of cure cycles on void content and mechanical properties of composite laminates in order to optimize the time for the process applied pressure. Hsiao et al. [7] presented a study of the direct cure kinetics characterization during liquid composite molding. In their study, a genetic algorithm coupled with onedimensional cure simulations was used to determine the cure kinetic parameters.

The present paper introduces an analytical and experimental investigation of cure cycle effect on high-temperature polymer composite structures molded by vacuum assisted resin transfer molding (VARTM). Thermal and resin cure analysis is performed to model the cure cycle of the VARTM process. The temperature and cure variations with time are determined by solving the three-dimensional transient energy and species equations within the composite part. 
Several case studies were investigated by the developed analytical model. The same cases were also experimentally investigated to determine the ultimate tensile strength for each case.

\section{Analytical Investigation}

The current analytical investigation aims at modeling the cure cycle of Cycom 5250-4-RTM resin molded by VARTM. Thermal and resin cure analysis is performed to determine the temperature and cure variations with time in the molded composite structure. The three-dimensional transient energy and species equations are coupled and solved simultaneously to determine the degree of cure as a function of the temperature and the time during the cure cycle as follows:

$$
\begin{gathered}
\rho C_{p} \frac{D T}{D t}=\nabla \cdot(k \nabla T)+S_{a}, \\
\Psi=\frac{C_{I}-C_{L}}{C_{I}}, \\
\frac{D \Psi}{D t}=R_{a},
\end{gathered}
$$

where $D \Psi / D t$ and $D T / D t$ are the material derivatives of the degree of cure and temperature, respectively. $C_{p}$ is the specific heat, and $k$ is the thermal conductivity of the resin. $C_{L}$ is the local concentration of the uncured resin, and $C_{I}$ is the initial concentration of uncured resin at any time. The exothermic chemical reaction releases heat acts as a source term, $S_{a}$, in the energy equation, and is given by

$$
S_{a}=C_{I}(\Delta H) R_{a}
$$

where $\Delta H$ is the heat of reaction and $R_{a}$, the reaction rate term, is given by the autocatalytic kinetic model presented by [8] as follows:

$$
\begin{gathered}
\frac{D \Psi}{D t}=\left(K_{1}+K_{2} \Psi\right)(1-\Psi)^{n} \\
K_{1}=A_{1} \exp \left(-\frac{E_{k 1}}{R T}\right) \\
K_{2}=A_{2} \exp \left(-\frac{E_{k 2}}{R T}\right)
\end{gathered}
$$

where $K_{1}$ and $K_{2}$ are the reaction rate constants, $A_{1}$ and $A_{2}$ are the Arrhenius constants, $E_{k}$ is the activation energy, $R$ is the universal gas constant, and $n$ is the order of the reaction. Lumped properties based on weight average thermophysical properties were used in the energy and species equations. The properties were determined as follows [3]:

$$
\begin{gathered}
\rho=\frac{\rho_{r} \rho_{f}}{\rho_{r} w_{r}+\rho_{f} w_{f}}, \\
k=\frac{k_{r} k_{f}}{k_{r} w_{r}+k_{f} w_{f}}, \\
c_{p}=w_{r} c_{p r}+w_{f} c_{p f}, \\
w_{f}=\frac{V_{f}}{V_{f}+\left(\rho_{r} / \rho_{f}\right)\left(1-V_{f}\right)}, \\
w_{r}=1-w_{f},
\end{gathered}
$$

where $\rho, \rho_{f}$, and $\rho_{r}$ are the densities; $k, k_{f}$, and $k_{r}$ are the thermal conductivities; $c_{p}, c_{p f}$, and $c_{p r}$ are the specific heats of the composite, the fiber, and the resin, respectively; $w_{f}$ and $w_{r}$ are the weight fractions of the fiber fabric and the resin, respectively; and $V_{f}$ is the fiber volume fraction.

\section{Analytical Modeling}

A MATLAB code was written, using the finite difference technique to solve for the thermal and cure histories in the cure cycle [9]. The energy and the species equations, (1) and (2), were solved together simultaneously. Temperature field is determined in the molded part at each time step. Then, the degree of cure is determined by integration of (3) with time. The degree of cure and the source heat were assumed to be zero at time zero. The reaction kinetics, for Cycom 5250-4-RTM resin, was determined by using a differential scanning calorimeter (DSC) [8]. The DSC measured the reaction exthotherm as a function of time as shown in (5). Table 1 summarizes the parameters of the kinetic model, obtained from [8].

\section{Case Study}

The developed model was used to get complete temperature and cure histories of the molded composites. Several case studies were investigated by the developed model. Table 2 shows the investigated cases. In each case, the mold temperature was raised to $120^{\circ} \mathrm{C}$ and kept at this temperature during the resin infusion. Then the mold was heated up to the maximum cure temperature, with a certain heating rate, and kept for four hours as shown in Table 2. After that, the mold was kept at $227^{\circ} \mathrm{C}$ for two hours as a postcure stage.

Figure 1 shows complete temperature and cure histories for Case 1 , with $194^{\circ} \mathrm{C}$ maximum cure temperature, $1.39^{\circ} \mathrm{C} / \mathrm{min}$ heating rate, and 2 hours postcure time at $227^{\circ} \mathrm{C}$. The figure shows that the rate of degree of cure sharply increases until the degree of cure reaches about $80 \%$. Then the curve is leveled off with a very low rate of increase till the end of the cure cycle. As shown in the figure, at the end of the 4 -hour cure stage, the degree of cure is $97.5 \%$, and after 2 hours of postcure the degree of cure reached $98.8 \%$. So, the postcure increased the degree of cure by $1.3 \%$. 
TABLE 1: Kinetic parameters for 5250-4-RTM resin.

\begin{tabular}{lccccc}
\hline $\begin{array}{l}\text { Arrhenius constant, } \\
A_{1}(\mathrm{l} / \mathrm{s})\end{array}$ & $\begin{array}{c}\text { Arrhenius constant, } \\
A_{2}(1 / \mathrm{s})\end{array}$ & $\begin{array}{c}\text { Activation energy, } \\
E_{k 1}(\mathrm{~kJ} / \mathrm{mole})\end{array}$ & $\begin{array}{c}\text { Activation energy, } \\
E_{k 2}(\mathrm{~kJ} / \mathrm{mole})\end{array}$ & $\begin{array}{c}\text { Heat of reaction, } \\
\Delta H(\mathrm{k} J / \mathrm{kg})\end{array}$ & $\begin{array}{c}\text { Order of reaction, } \\
n\end{array}$ \\
\hline 0.815 & 40.2 & 29.3 & 37.3 & 249.8 & 2 \\
\hline
\end{tabular}

TABLE 2: Some cases used to produce composite panel by VARTM.

\begin{tabular}{lccc}
\hline $\begin{array}{l}\text { Case } \\
\text { number }\end{array}$ & $\begin{array}{c}\text { Maximum cure } \\
\text { temperature } \\
\left({ }^{\circ} \mathrm{C}\right)\end{array}$ & $\begin{array}{c}\text { Heating rate } \\
\left({ }^{\circ} \mathrm{C} / \mathrm{min}\right)\end{array}$ & $\begin{array}{c}\text { Postcure time at } \\
227^{\circ} \mathrm{C}(\mathrm{h})\end{array}$ \\
\hline Case 1 & 194 & 1.39 & 2 \\
Case 2 & 194 & 0.56 & 2 \\
Case 3 & 183 & 1.39 & 2 \\
Case 4 & 205 & 1.39 & 2 \\
\hline
\end{tabular}

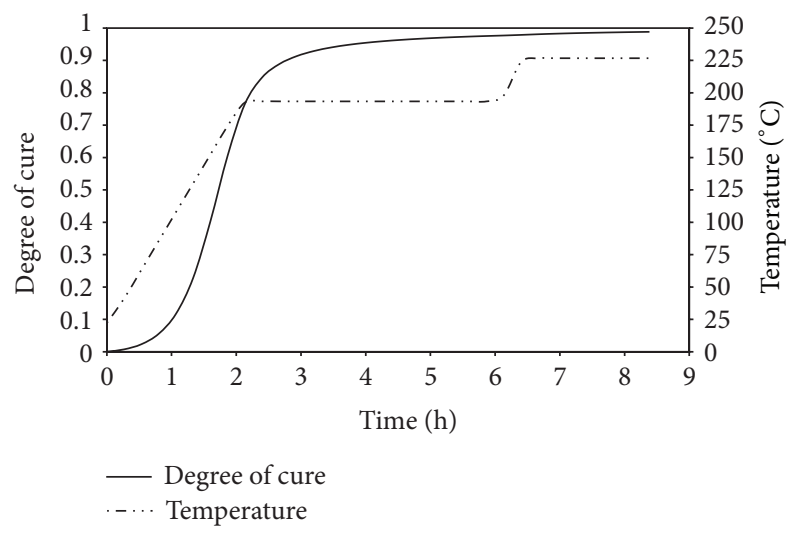

FIGURE 1: Cure and temperature histories for Case 1.

Figure 2 shows the distribution of degree of cure through the thickness and along the length of the composite panel for Case 1 during curing stage, after one hour from the beginning of the cure cycle. Figure 3 shows the same distribution through the thickness and along the width of the panel. These two sections were taken at the middle of the panel. A section at the middle is a good representative for the panel, based on the observation of several sections taken along the length and the width with almost no difference. The two figures show that the distribution of degree of cure for any layer along the length or the width is almost constant except at the edges. But the main change occurs across the panel thickness, where the degree of cure decreases gradually from the bottom to the top, from 75.7 to $73.5 \%$, within a range of $2.2 \%$. It is believed that using a heat blanket under the mold, as a heat source, is the reason for that difference across the thickness. Figure 4 shows the temperature distribution through the thickness and along the length of the composite panel for Case 1 at the end of the cure cycle. The temperature distribution shows a trend similar to the distribution of degree of cure. At the end of the cure cycle, the degree of cure is almost the same across the part within a range of $0.012 \%$ as shown in Figure 5.

Another case was studied, Case 2, with a low heating rate of $0.56^{\circ} \mathrm{C} / \mathrm{min}$, but with the same cure temperature and

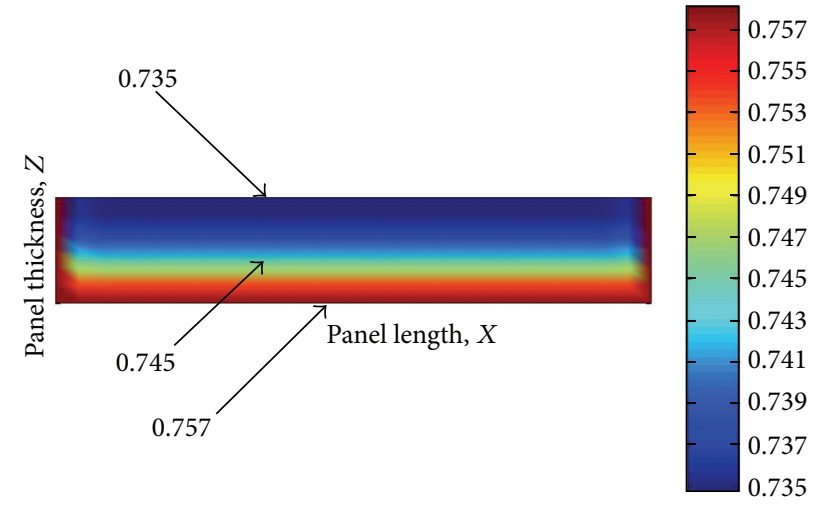

FIGURE 2: Distribution of degree of cure through the panel thickness along the length of the composite panel after 1 hour of the cure cycle.

postcure time as in Case 1. The complete temperature and cure histories for Case 2 are shown in Figure 6. Figure 7 shows a comparison between the cure histories for these two cases, 1 and 2. In Case 1, with a higher heating rate, it took the material 66 minutes to reach about $80 \%$ degree of cure, while in Case 2, with a lower heating rate, it took about 115 minutes to reach the same degree. However, the cure cycle for Case 1 was completed in 432 minutes with a $98.81 \%$ degree of cure, while in Case 2 the cure cycle time and the degree of cure were 510 minutes and $98.89 \%$, respectively. So, the cure cycle for Case 2 was 78 minutes longer than Case 1.

The effect of maximum cure temperature on the trend of degree of cure was studied through the comparison of two cases, 3 and 4, with the same heating rate and postcure time but with different maximum cure temperature. In Case 3 the maximum cure temperature was $183^{\circ} \mathrm{C}$, while it was $205^{\circ} \mathrm{C}$ in Case 4. Figure 8 shows a comparison between the cure histories for these two cases. In the first 48 minutes of the cure cycle, the degree of cure for both cases was the same, $62 \%$. Then the case with the higher cure temperature reached a higher degree of cure than the case with the lower one in a shorter time. Both cases reached the same degree of cure at the end of the cure stage and right before the postcure stage.

The presented analytical cases were also investigated experimentally to determine the maximum tensile strength for each case. A two-layer laminate was molded by VARTM process. The materials used are AS4-8H carbon-fiber fabric and a high-temperature polymer called Cycom 52504-RTM. Full description of the experimental setup was reported in a previous publication by the authors of [10]. Room temperature tension tests were performed using ASTM D3039 standard test method for tensile properties of polymer matrix composite materials. Specimens, used in the test, were $200 \mathrm{~mm}$ long, $25 \mathrm{~mm}$ wide, and on average $0.79 \mathrm{~mm}$ 
TABle 3: Process parameters effect on tensile strength for each case.

\begin{tabular}{lccccc}
\hline $\begin{array}{l}\text { Case } \\
\text { number }\end{array}$ & $\begin{array}{c}\text { Maximum cure } \\
\text { temperature }\left({ }^{\circ} \mathrm{C}\right)\end{array}$ & $\begin{array}{c}\text { Heating rate } \\
\left({ }^{\circ} \mathrm{C} / \mathrm{min}\right)\end{array}$ & $\begin{array}{c}\text { Postcure time at } \\
227^{\circ} \mathrm{C}(\mathrm{h})\end{array}$ & $\begin{array}{c}\text { Number of } \\
\text { samples tested }\end{array}$ & $\begin{array}{c}\text { Maximum tensile } \\
\text { strength }(\mathrm{MPa})\end{array}$ \\
\hline Case 1 & 194 & 1.39 & 2 & 5 & 856 \\
Case 2 & 194 & 0.56 & 2 & 5 & 825 \\
Case 3 & 183 & 1.39 & 2 & 5 & 884 \\
Case 4 & 205 & 1.39 & 2 & 5 & 817 \\
\hline
\end{tabular}

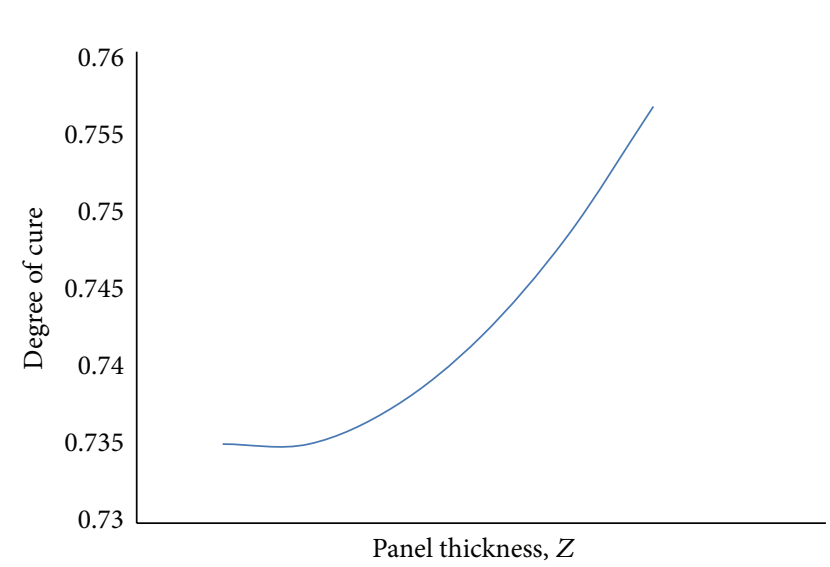

(a)

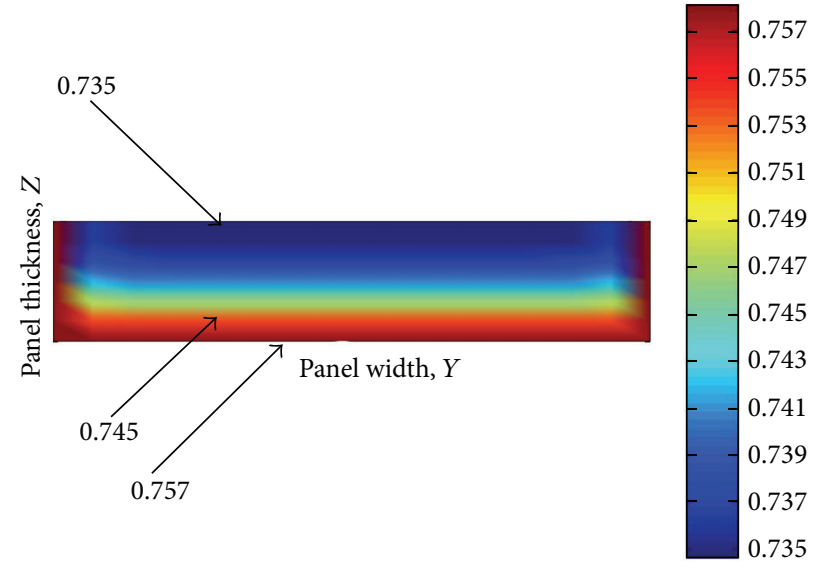

(b)

FIgURE 3: Distribution of degree of cure through the panel thickness along the width of the composite panel after 1 hour of the cure cycle.

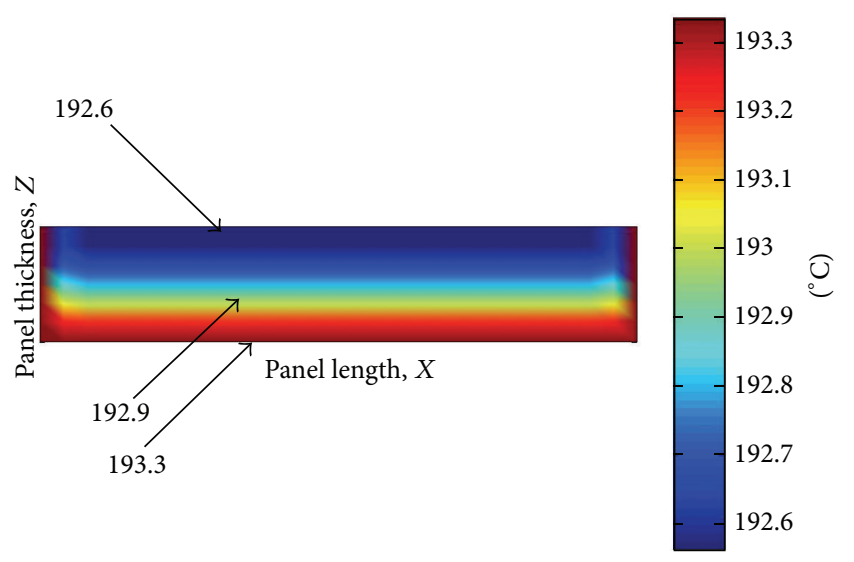

FIGURE 4: Distribution of temperature through the panel thickness along the length of the composite panel at the end of cure cycle.

thick. The machine which was used in the testing is Series 812 Materials Test System from MTS Systems Corporation. Hydraulic grips were used with a gripping pressure of $10 \mathrm{MPa}$. The tension test was performed using a constant head speed of $1.27 \mathrm{~mm} / \mathrm{min}$. A data acquisition system based on LABVEIW software was used to collect the test data.

Table 3 shows the effect of process parameters on ultimate tensile strength. Each case was repeated 5 times; as the heating rate reduced from $1.39^{\circ} \mathrm{C} / \mathrm{min}$, in Case 1 , to $0.56^{\circ} \mathrm{C} / \mathrm{min}$, in Case 2, the tensile strength decreased by $3.6 \%$. Increasing the maximum cure temperature resulted in decreasing

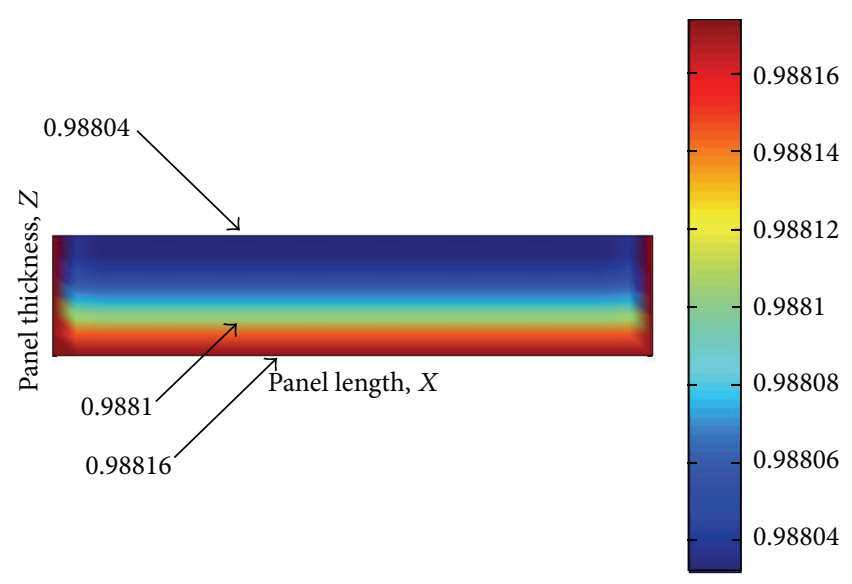

FIGURE 5: Distribution of degree of cure through the panel thickness along the length of the composite panel at the end of cure cycle.

the maximum tensile strength by $7.6 \%$. The highest tensile strength was found in Case 3 with the lowest maximum cure temperature of $183^{\circ} \mathrm{C}$ and a heating rate of $1.39^{\circ} \mathrm{C} / \mathrm{min}$.

During cure and postcure stages, the cross-linking mechanism involves two main steps. These two steps are carboncarbon double bonds $(\mathrm{C}=\mathrm{C})$ opening and dehydration of hydroxyl groups. The first step improves the composite mechanical properties, while the second step deteriorates the mechanical properties. As the maximum cure temperature increases, the effects of the rate of dehydration become more 


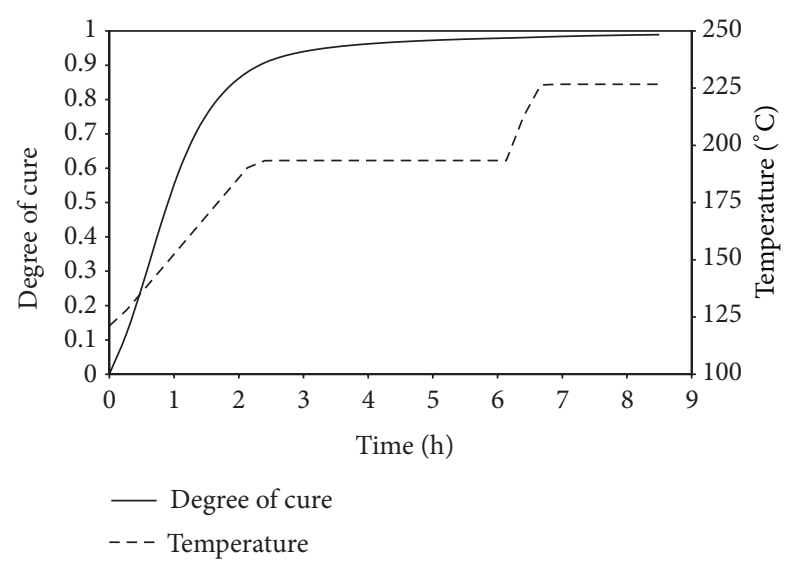

Figure 6: Cure and temperature histories for Case 2.

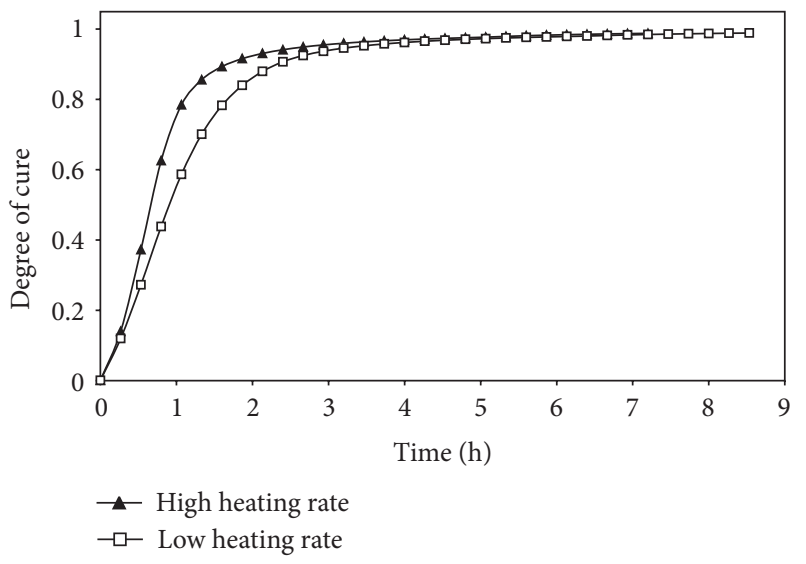

FIgURE 7: Cure history comparison for Cases 1 and 2.

pronounced as compared with the mechanism of carboncarbon double bonds $(\mathrm{C}=\mathrm{C})$ opening. Since curing the resin at a high temperature, for the same time as at a low temperature, increases the possibility of water molecules diffusion out of the polymer, which leads to more defects. While at a low maximum cure temperature, within the range used in the experimental design, the carbon-carbon double bonds $(\mathrm{C}=\mathrm{C})$ opening dominates the mechanism of cross linking, which improves the composite mechanical properties. Decreasing the heating rate form Case 1 to Case 2 increases the cure cycle time by an hour which, as well, increases the polymer dehydration, which deteriorates the mechanical properties. So, curing time, which is 4 hours in this study, at a low maximum cure temperature of $183^{\circ} \mathrm{C}$ with $1.39^{\circ} \mathrm{C} / \mathrm{min}$ heating rate is enough to reach the maximum degree of cure based on carbon-carbon double bonds $(\mathrm{C}=\mathrm{C})$ opening mechanism, which improves the properties.

\section{Conclusions}

This paper presents an analytical and experimental investigation of cure cycle effect on carbon-fiber reinforced polymer

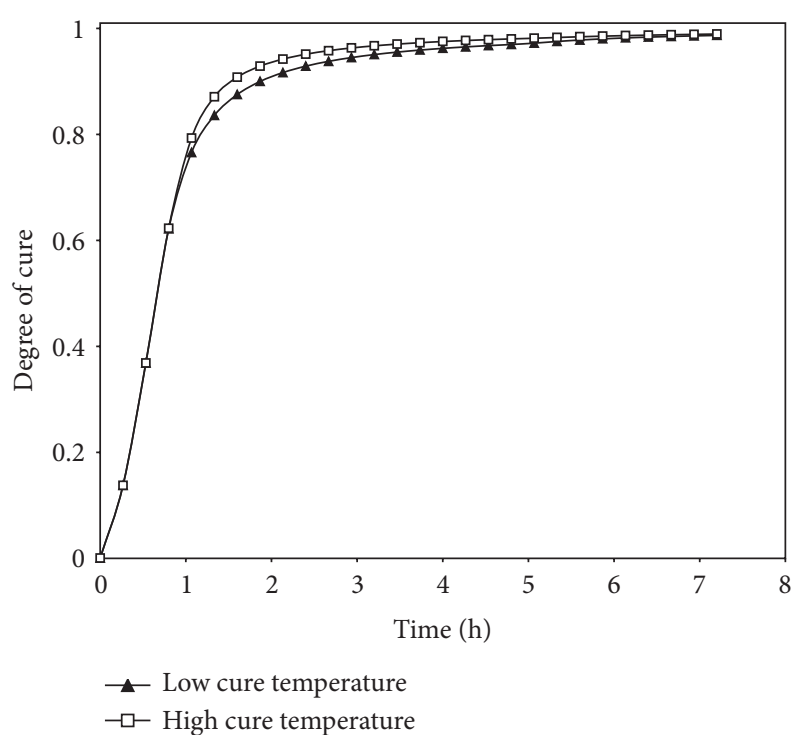

FIgURE 8: Cure history comparison for Cases 3 and 4.

composites molded by VARTM. The investigated composite structure was composed of high-temperature polymer (Cycom 5250-4-RTM) and eight harness woven fiber fabrics. The findings of this study show that, within the range used for each parameter in the experimental design, a maximum cure temperature of $183^{\circ} \mathrm{C}$, a postcure time of 2 hours at $227^{\circ} \mathrm{C}$, and a heating rate of $1.67^{\circ} \mathrm{C} / \mathrm{min}$ helped to produce composite structures with high ultimate tensile strength tested at room temperature. The developed analytical model can determine the degree of cure as functions of time and temperature during the cure cycle, as well as, the distribution of degree of cure and temperatures within the part thickness at any time of the cure cycle. This analytical-experimental investigation provides capability for robust process design and characterization of process induced damage. This study helps in developing a science based technology for the VARTM process for the understanding of the process behavior and the effect of the cure cycle on the properties of the molded composites.

\section{Conflict of Interests}

The author acknowledges that there is no any kind of conflict of interests regarding this paper.

\section{Acknowledgments}

The author wishes to acknowledge the support of the Airtech Advanced Materials Group, Hexcel Corporation, and Cytec Engineered Materials.

\section{References}

[1] H. Golestanian and A. S. El-Gizawy, "Cure dependent lamina stiffness matrices of resin transfer molded composite parts with 
woven fiber mats," Journal of Composite Materials, vol. 31, no. 23, pp. 2402-2423, 1997.

[2] C. Yiyun and H. Pingsheng, "Cure behavior of epoxy resin E51-melamine phosphate (MP)-MeTHPA-2, 4-EMI halogenfree fire retardant composite by the dynamic torsional vibration method," Journal of Composite Materials, vol. 40, no. 13, pp. 1215-1223, 2006.

[3] X. Yan, "Consolidation and cure simulations for laminated composites," Journal of Composite Materials, vol. 40, no. 20, pp. 1853-1869, 2006.

[4] A. Khattab and A. S. El-Gizawy, "Analytical and experimental evaluation of elastic properties of vacuum assisted resin infusion molded polymer composites with eight-harness woven fiber mats," Polymer Composites, vol. 29, no. 1, pp. 63-71, 2008.

[5] Y. K. Kim and I. M. Daniel, "Cure cycle effect on composite structures manufactured by resin transfer molding," Journal of Composite Materials, vol. 36, no. 14, pp. 1725-1743, 2002.

[6] L. Liu, B. M. Zhang, D. F. Wang, and Z. J. Wu, "Effects of cure cycles on void content and mechanical properties of composite laminates," Composite Structures, vol. 73, no. 3, pp. 303-309, 2006.

[7] K. T. Hsiao, R. Little, O. Restrepo, and B. Minaie, "A study of direct cure kinetics characterization during liquid composite molding," Composites Part A, vol. 37, no. 6, pp. 925-933, 2006.

[8] R. Srinivasan, T. J. Wang, and L. J. Lee, "Chemorheology of high temperature RTM resins," in Proceedings of the 53rd Society of Plastics Engineers Technical Conference (ANTEC' 95), pp. 30163029, October 1995.

[9] S. V. Patanakar, Numerical Heat Transfer and Fluid Flow, vol. 59, McGraw-Hill, New York, NY, USA, 1980.

[10] A. Khattab and A. S. El-Gizawy, "Characterization of processinduced properties in vacuum assisted resin infusion molding of high temperature polymer composites," Journal of Advanced Materials, vol. 40, no. 3, pp. 51-68, 2008. 

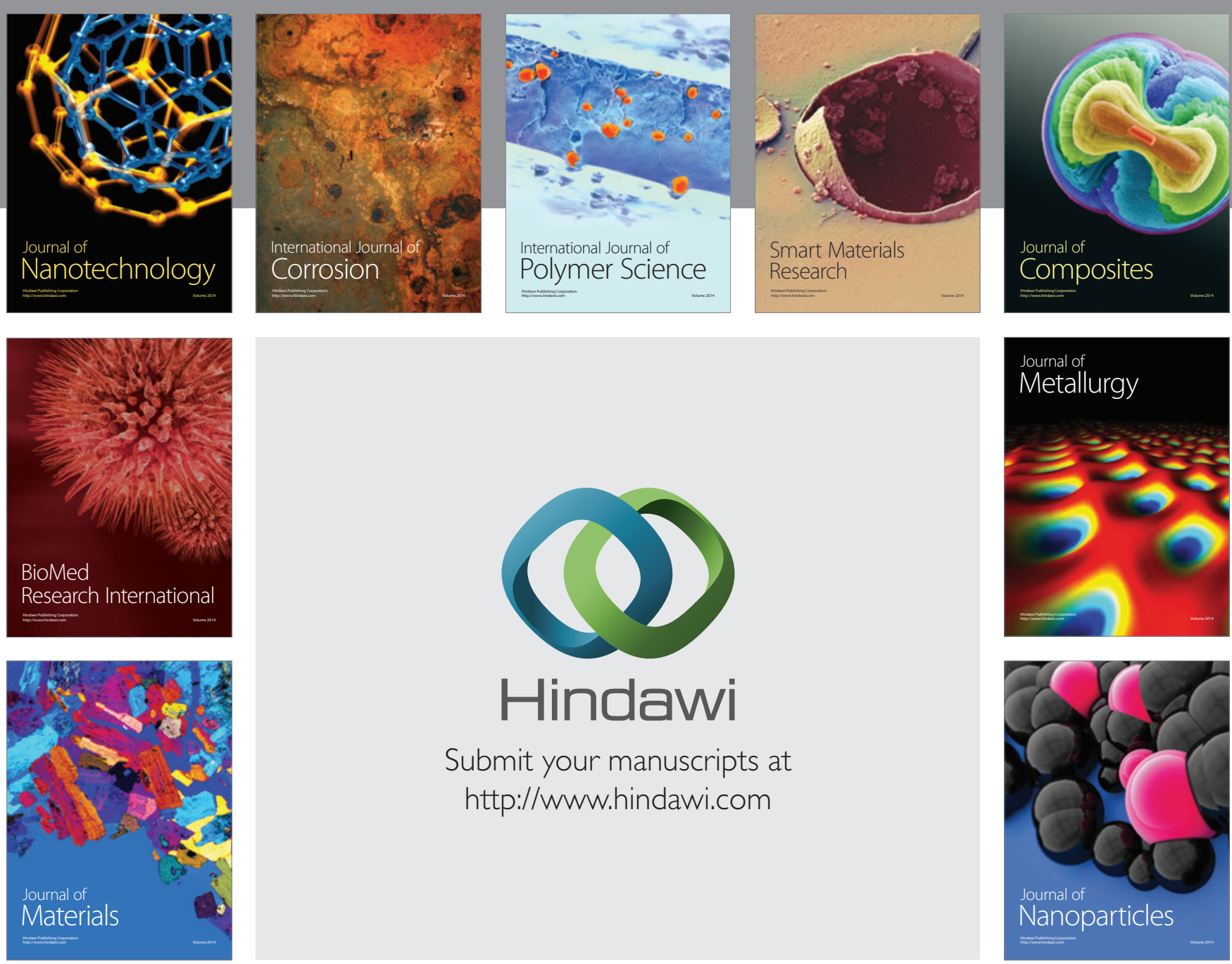

Submit your manuscripts at http://www.hindawi.com
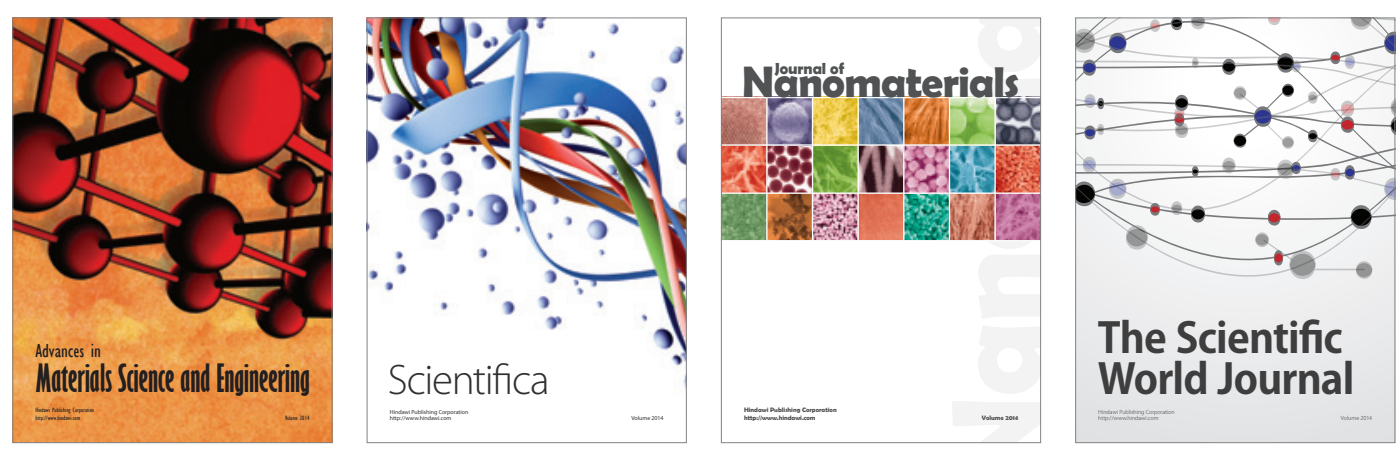

\section{The Scientific World Journal}
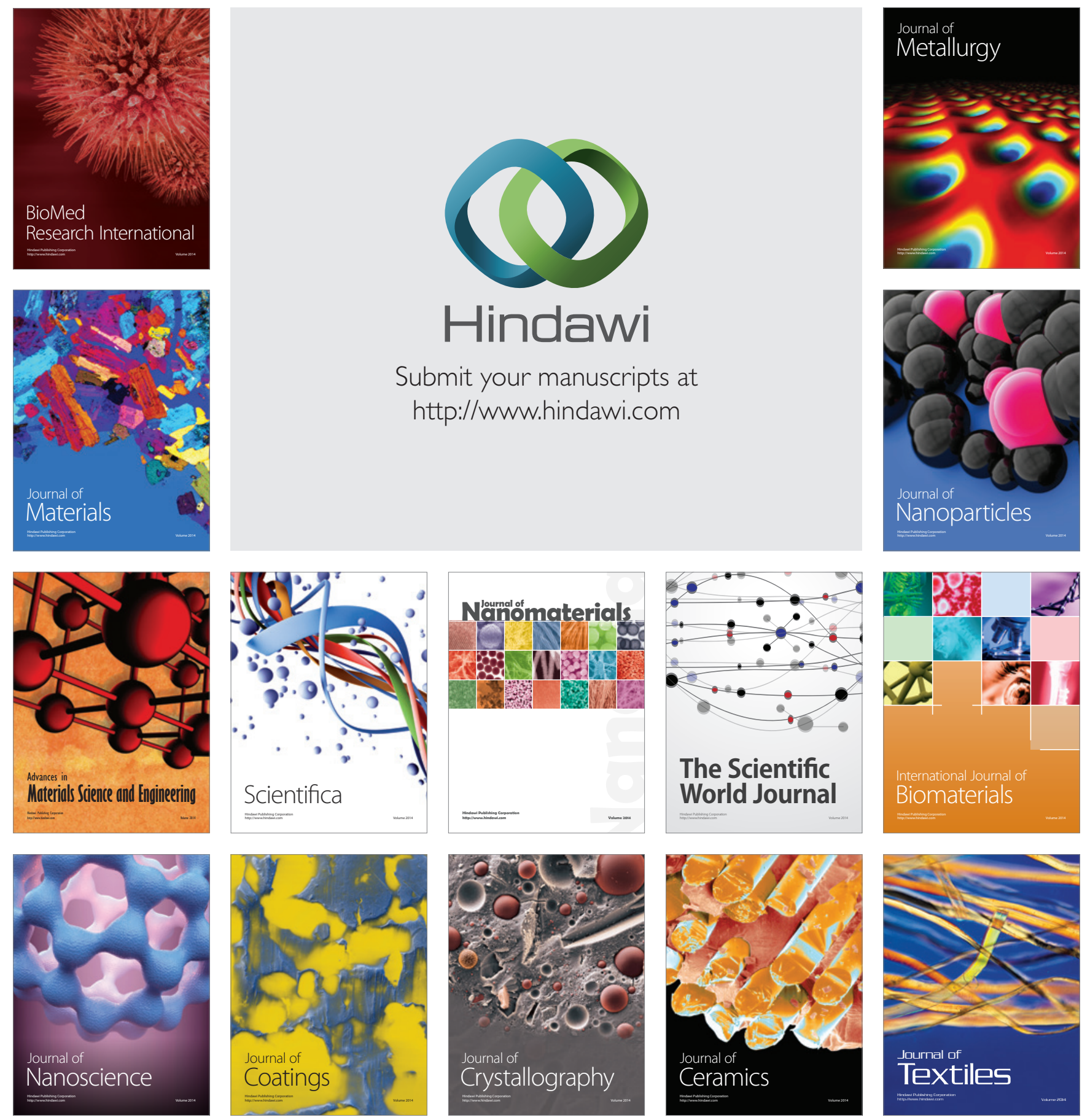